\title{
Risk factors for embolisation in patients with left ventricular thrombi and acute myocardial infarction
}

\author{
KARL-ARNE JOHANNESSEN, JAN ERIK NORDREHAUG, \\ GERHARD VON DER LIPPE, STEIN EMIL VOLLSET
}

From the Cardiology Section, Diakonissehjemmets Hospital, Bergen, Norway

SUMMARY Risk factors for systemic embolisation in patients with ventricular thrombi caused byjo an acute myocardial infarction were studied in 150 consecutive patients with an infarction of the anterior wall. Serial echocardiograms were performed 2-10 days after the acute event and patients were followed up for three months. Anticoagulation treatment was started only after the detectionf of thrombi. Of the 55 patients in whom a thrombus developed, $15(27 \%)$ had peripheral embolp between 6-62 days; but only two (2\%) of 95 patients without thrombus had emboli. Among 15 variables, the best single predictors of embolisation were age $>68$ years $(80 \%$ sensitive, $85 \%$ specific), pendulous thrombus $(60 \%, 93 \%)$, and independent thrombus mobility $(60 \%, 85 \%) \frac{1}{6}$ Logistic regression analysis showed that a formula that included patient age, thrombus area, and the length of thrombus in the ventricular lumen predicted embolisation (sensitivity $87 \%$ specificity $88 \%$ ). There was no correlation between age and the thrombus variables.

The risk of embolisation from left ventricular thrombi in acute anterior myocardial infarction can be accurately assessed from patient age and echocardiographic features. The risk of peripheraf emboli is high in patients with left ventricular thrombi and those aged $>68$.

Left ventricular thrombi were detected by cross sectional echocardiography in $28-40 \%$ of patients with anterior wall acute myocardial infarction but rarely occurred with infarcts at other sites. ${ }^{1-8}$ The reported risk of embolisation after the formation of a thrombus ranges from 0 to $37 \% \cdot{ }^{1-13}$ Several of these reported studies were retrospective or small.

Several predictors of embolisation have been defined in patients who have left ventricular thrombi. In particular, mobile and pendulous thrombi have been associated with an increased frequency of embolisation. But the frequency of embolisation in patients with thrombus protrusion into the left ventricle $(22 \%-100 \%)$ or thrombus mobility $(35 \%-$ $100 \%$ ) has varied widely. ${ }^{-14}$ These wide differences may be associated with differences in patient populations (recent versus remote infarctions), differences in anticoagulant treatment, or with the fact that some of the studies were retrospective. ${ }^{9-11}$ Several studies found that thrombi with very different echocar-

Requests for reprints to Dr Karl-Arne Johannessen, Cardiology Section, Medical Department, University Hospital, 5016 Haukeland Hospital, Bergen, Norway.

Accepted for publication 16 March 1988 diographic appearances were associated with embol⿳⺈ isation. ${ }^{14-16}$ Moreover, one recent study of acute thrombi noted considerable spontaneous variabilit of both thrombus mobility and shape, which makes these features less useful predictors for embol 1 isation. ${ }^{12}$ So, further data are needed on predictors of embolisation.

The objectives of the present prospective stud\% were to define the risk of embolism associated wit? left ventriclar thrombi in patients with a first acutê anterior infarction and to identify predictors of embolisation.

\section{Patients and methods}

One hundred and fifty consecutive patients with a initial acute anterior wall myocardial infarction werg examined prospectively by cross sectional echocat diography for the development of left ventricular thrombi. The criteria for acute myocardial infarctio were (in addition to a typical history): (a) the development of $Q$ waves and/or ST-elevation of $\geqslant \$$ $\mathrm{mm}$ in standard leads $\mathrm{I}$ and $\mathrm{aVL}$ and/or $\geqslant 2 \mathrm{~mm}$ i precordial leads V $1-6$ followed by $T$ wave inversio and $(b)$ a transient increase in aspartate aminotransferase to more than twice the upper limit of normat. 
Patients taking anticoagulants or platelet inhibiting drugs were excluded from the study.

None of the patients received any type of anticoagulation before the diagnosis of a left ventricular thrombus. Only patients who developed a definite left ventricular thrombus were given intravenous heparin (therapeutic level for partial thrombin time $70-140$ seconds $)^{17}$ and oral warfarin (therapeutic Thrombotest level $5-10 \%) \cdot{ }^{18}$ Heparin was stopped when the Thrombotest became normal, but warfarin was continued throughout the study period. Patients who did not develop a thrombus were not given anticoagulants, and anticoagulants were not started in 15 patients who had contraindications to anticoagulants. Platelet inhibiting drugs and prophylactic antiarrhythmic drugs were not used.

\section{CROSS SECTIONAL ECHOCARDIOGRAPHY}

Between days 2 and 10 after the acute infarction serial cross sectional echocardiographic examinations were performed with a Toshiba SSH-10 phased array sector scanner. All patients had at least three examinations; if no thrombus was diagnosed, patients were generally examined on day 2,6 , and 10 . Once a thrombus was suspected, more frequent examinations were performed and if necessary continued after day 10 to make a definite diagnosis. Patients who did not have a left ventricular thrombus present within 10 days were not examined further, while patients in whom a thrombus had been detected had monthly echocardiograms.

Patients were examined while they were lying in the left lateral decubitus position with the head slightly raised. Our diagnostic criteria for thrombi were: $(a)$ intracavitary mass visible with two markedly different sector orientations; $(b)$ an intracavitary mass with a definite margin; and $(c)$ clear delineation of the underlying endocardium. Studies were interpreted by two independent observers. There was disagreement on six patients, but a consensus was reached by both observers when they reviewed the serial scans. Patients were not excluded because of poor image quality; one observer considered the images to be of poor quality in 11 patients and the other observer considered image quality to be poor in nine of the same patients. None of the patients who had poor image quality were diagnosed as having a thrombus.

\section{CHARACTERISATION OF THROMBI}

Thrombi were characterised both visually and quantitatively.

\section{(a) Visual features}

Thrombi were classified as pendulous or flat and as mobile or immobile. Mobility was diagnosed if a

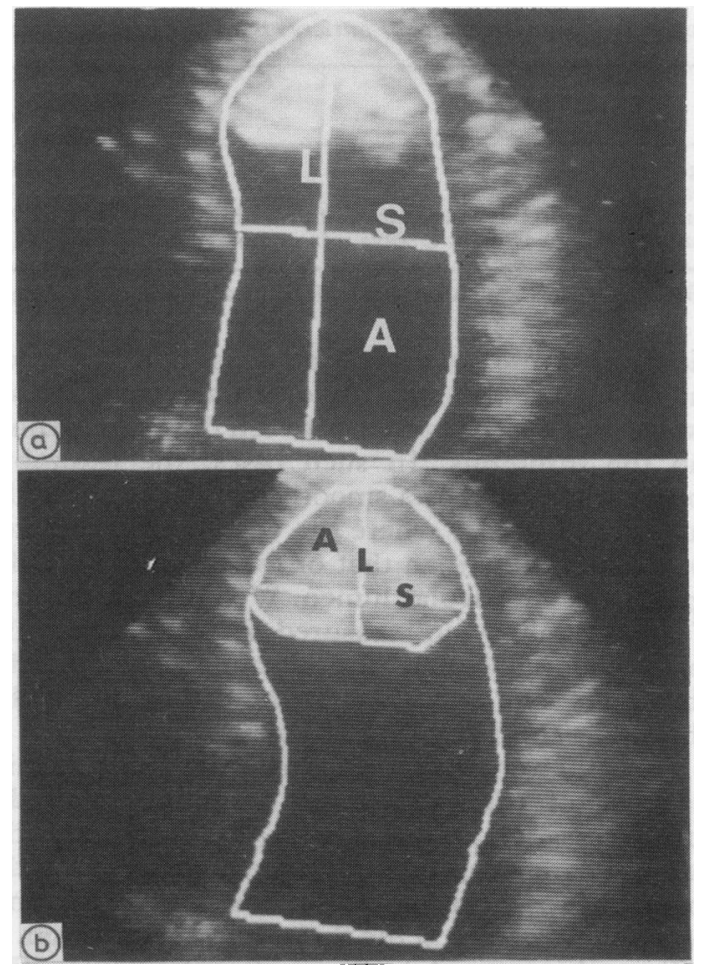

Fig 1 Area $A$ of the manually drawn outline of the left ventricle (a) and left ventricular thrombus (b) with the long axis ( $L$ ) and short axis $(S)$.

thrombus or parts of it showed movement that differed from that of the underlying myocardium during the cardiac cycle. In addition, a thrombus was classified as either homogeneous or heterogeneous. A thrombus was classified as heterogeneous if parts of it had a shaggy margin or if its centre was echolucent.

\section{(b) Quantitative features}

We used a light pen and overlay technique, ${ }^{19}$ to calculate the area, long axis, and short axis of both the ventricle and the thrombus (fig $1 \mathrm{a}-\mathrm{b}$ ). The area under the manually drawn ventricular end diastolic (peak of $\mathbf{R}$ wave in standard electrocardiographic lead I) silhouette was computed in the apical four chamber view with the transducer position that gave the largest ventricular area. We measured the long axis from the middle of the mitral valve to the apex in the same view and the short axis as the transverse diameter in the same four chamber view at the middle of the long axis (fig 1a).

We measured the thrombus on the view in which it was largest and had a definite margin. We avoided transducer positions that might have included myocardium as well as thrombus. Although ven- 
Table 1 Characteristics of patients with left ventricular thrombi ( $L V T$ ) and peripheral emboli (PE)

\begin{tabular}{|c|c|c|c|c|}
\hline & $\begin{array}{l}\text { Patients with LVT } \\
\text { and } P E(n=15)\end{array}$ & $\begin{array}{l}\text { Patients with } L V T \\
\text { and no } P E(n=40)\end{array}$ & $p$ & 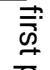 \\
\hline $\begin{array}{l}\text { Age (yr) } \\
\text { Peak ASAT (U/l) } \\
\text { Time from infarction to diagnosis of thrombus (days) } \\
\text { Number of patients with } Q \text { wave infarctions }\end{array}$ & $\begin{array}{l}68 \cdot 9(6 \cdot 0)(55-79) \\
359(224)(119-820) \\
7 \cdot 2(3 \cdot 4)(3-16) \\
11(73 \%)\end{array}$ & $\begin{array}{l}59 \cdot 1(8 \cdot 1)(35-76) \\
333(146)(83-699) \\
6 \cdot 5(3 \cdot 9)(2-23) \\
31(78 \%)\end{array}$ & $\begin{array}{l}<0 \cdot 001 \\
\text { NS } \\
\text { NS } \\
\text { NS }\end{array}$ & $\frac{\bar{\sigma}}{\frac{\bar{\sigma}}{\frac{\pi}{D}}}$ \\
\hline
\end{tabular}

tricular thrombi are more echo dense than the blood and the endocardium and myocardium, we could not always identify the border between the endocardium and the thrombus. In such cases, the thrombus border was drawn as a smoothened curve along the endocardial border where the echo density became considerably less than that of the thrombus border against the ventricular lumen. We outlined the area of the thrombus and measured the length from the apical endocardium to the intraventricular border (thrombus long axis, $L$ ) and the orthogonal width (thrombus short axis, S) (fig 1b).

Thrombi were measured when there was a definite diagnosis of a left ventricular thrombus. This did not necessarily coincide with the first day the thrombus was suspected. Subsequent changes in the appearance of the thrombus were used to change only the visual variables in the thrombus classification.

Two observers did all the measurements. The interobserver variability in the quantitative analysis of the 55 thrombi was $< \pm 15.5 \%$ for areas, $< \pm 8 \%$ for long axis, and $< \pm 14.7 \%$ for transverse axis measurements. The intraobserver variability was less than this.

\section{PERIPHERAL EMBOLI}

All patients were followed for three months for the occurrence of peripheral emboli. Patients were told to report immediately if symptoms of peripheral embolisation developed.

Peripheral embolisation was defined as: (a) acute arterial occulsion in an extremity or $(b)$ acute cerebrovascular accident with neurological symp- toms and findings that persisted for at least one hour. Dizziness, syncope, or symptoms with no abnormale clinical neurological findings were not accepted. We did not attempt to diagnose emboli in the? abdominal circulation. Computerised cerebralo tomography was done on eight of the 12 patients with? thrombus and stroke and in two patients with stroke ${ }_{+}$ but no thrombus. All patients with a diagnosis of emboli were examined on the day of the embolic ${ }_{-}$ event.

\section{STATISTICAL ANALYSIS}

We used Fisher's exact test to analyse discontinuous data and stepwise logistic regression to compare the $\infty$ data from patients with and without peripheral ${ }^{\infty}$ emboli. ${ }^{20}$ Mean values of the variables from the two groups were compared by the Wilcoxon-Mann Whitney test, and correlations between normally distributed continuous variables were analysed by linear regression. All tests were two sided, and $p \propto$ values of $<0.05$ were regarded as significant. Results $\vec{\circ}$ are given as mean (1 SD).

\section{Results}

Of the 150 patients, $55(37 \%)$ developed a left ventricular thrombus and $95(63 \%)$ did not. Among the 95 patients without a diagnosis of thrombi, only 3 . two $(2 \%)$ suffered cerebrovascular accidents (8 and 14 days) after the infarction. Fifteen $(27 \%)$ of the 553 patients with thrombi had peripheral emboli fromo five to 62 days after the acute infarction. Ten $(67 \%)$ of the 15 embolic events occurred during the firsto

Table 2 Computerised measures of the left ventricle and left ventricular thrombi

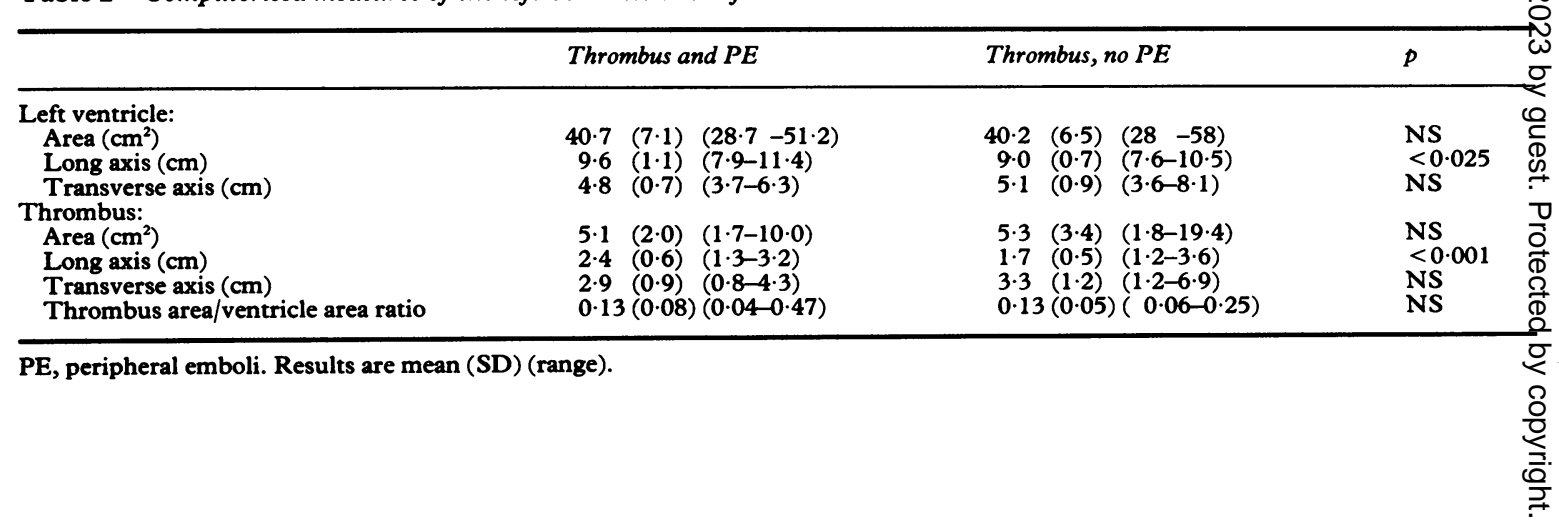


Table 3 Predictive value of patient age and visual variables of left ventricular thrombi (LVT) for peripheral emboli (PE)

\begin{tabular}{lllll}
\hline & $\begin{array}{l}\text { Patients with } L V T \text { and } P E \\
(n=15)\end{array}$ & $\begin{array}{l}\text { Patients with LVT and no PE } \\
(n=40)\end{array}$ & $\begin{array}{c}\text { Sensitivity } \\
(\%)\end{array}$ & $\begin{array}{l}\text { Specificity } \\
(\%)\end{array}$ \\
\hline Patient age > 68 years & 12 & 6 & 80 & 85 \\
Independent movement & 9 & 6 & 60 & 85 \\
Pendulous form & 9 & 3 & 60 & 92.5 \\
Variable echo density & 10 & 7 & 86.7 & 82.5 \\
\hline
\end{tabular}

three weeks after the acute infarction, and $12(80 \%)$ were cerebrovascular accidents. The mean age of the 55 patients with left ventricular thrombus was 61.8 (8.2) years compared with $61.5(10.0)$ years (NS) in the 95 patients without a thrombus.

Table 1 compares thrombus patients with and without emboli. The mean values of peak aspartate aminotransferase activity, time from onset of the infarction to diagnosis of thrombus, and the occurrence of $Q$ wave infarctions or transient arrhythmias during the first 10 days were not different in the 15 patients with (group 1) and the 40 patients without (group 2) peripheral emboli. Patients with peripheral emboli were significantly older than those without (68.9 (6.0) versus 59.1 (8.1), p < 0.001).

The long axis of the left ventricle was slightly longer in patients with emboli than in those without (table 2). In addition, the long axis of the thrombus was significantly greater in patients with emboli $(2.4$ $(0.6) \mathrm{cm}$ versus $1.7(0.5) \mathrm{cm}, \mathrm{p}<0.001)$. Other measurements of the ventricle or thrombus were not significantly different in groups 1 and 2. Only one of the 10 largest thrombi, as judged by thrombus area, formed emboli.

The predictive value of the following variables was analysed: patient age, sex, time from start of symptoms to admission, time from infarction to thrombus development, peak aspartate aminotransferase, left ventricular area, long and transverse axis, thrombus area, long and transverse axis, relation between thrombus area and ventricular area, independent movement of thrombus, echolucency of thrombus, and pendulousness of the thrombus.

Age was the best single predictor of peripheral embolus. Of the 55 patients with thrombus, 12 of 15 who had embolisation were $>68$ (sensitivity $=80 \%$ ) whereas only six patients without embolisation were $>68$ (specificity $=85 \%$ ) (table 3 ). Thus $12(68 \%$ ) of the 18 patients with thrombus who were aged $>68$ had emboli, whereas only two $(9 \%)$ of 22 patients $>68$ years without thrombi had a cerebrovasular accident $(\mathrm{p}<0.001)$.

The single best visual predictor of embolisation was pendulousness. Pendulous thrombi were present in nine of 15 patients with emboli compared with three of 40 patients without (sensitivity $60 \%$, specificity $93 \%$ ). The thrombus was mobile in nine of 15 patients with emboli and six of 40 without emboli (sensitivity $60^{\circ}{ }_{0}$, specificity $85^{\circ}{ }^{\circ}$ ). Of the 17 thrombi with variable echo density, 10 had central echolucency and seven had varying echo density without a central clearing.

The following predictive equation for peripheral embolisation that includes patient age $(Y)$, the thrombus area (A), and the long axis of the thrombus (L) was established by a stepwise logistic regression: (1) Probability of embolus $=1 /(1+\exp (1.05 \times \mathrm{A}$ $+25.2-0.284 \times \mathrm{Y}-5.67 \times \mathrm{L})$ ).

Figure 2 shows the calculated probabilities of embolisation in the patients with thrombi. We chose some arbitrary cut off points for the probability of emboli and calculated the corresponding sensitivity and specificity. A cut off of 0.35 gave the highest sensitivity and specificity of $85.6^{\circ}{ }_{0}$ and $87.5^{\circ} \mathrm{o}$ respectively (fig 2 ). Although retrospective choice of a cut off point may be sample specific, choosing other cut offs also resulted in good predictability, higher cut offs reduced sensitivity but increased specificity.

Although there was a significant correlation between thrombus area and length $(r=0.85, p<$ 0.001 ), there was no correlation between the patient age and thrombus area or length $(r=0.001$ and 0.09 respectively). None of the visual echocardiographic variables, however, gave additional predictive value to the logistic regression in (1).

Two of 15 patients with a left ventricular thrombus

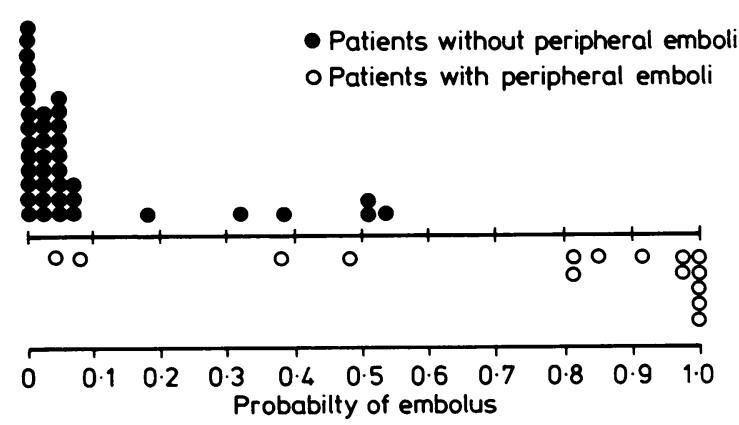

Fig 2 Distribution of the patients with left ventricular thrombi according to their calculated probabilities of peripheral emboli based on the formula: Probability of embolus $=1 / 11+\exp (1.05 \times A+25.2-5.67 \times L-$ $0.284 \times Y)(Y=$ patient age $)$. 
Table 4 Patients with acute vascular accidents (VA)

\begin{tabular}{lllll}
\hline & $\begin{array}{l}\text { Time (days) from } \\
\text { infarction to } \\
\text { diagnosis of: }\end{array}$ & $\begin{array}{l}\text { Duration } \\
\text { (days) of } \\
\text { anticoagulation } \\
\text { at time } \\
\text { of } V A\end{array}$ & $\begin{array}{l}\text { Location } \\
\text { of } V A\end{array}$ \\
\cline { 2 - 5 } No & LVT & $V A$ & 2 & CVA \\
\hline 1 & 4 & 6 & 13 & CVA \\
2 & 5 & 18 & 1 & CVA \\
3 & 5 & 6 & 6 & Left arm \\
4 & 8 & 14 & 9 & CVA \\
5 & 3 & 12 & 58 & CVA \\
6 & 4 & 62 & 16 & Right arm \\
7 & 7 & 23 & 8 & CVA \\
8 & 8 & 36 & 9 & CVA \\
9 & 7 & 16 & 6 & CVA \\
10 & 5 & 15 & 6 & Left leg \\
11 & 16 & 22 & 18 & CVA \\
12 & 8 & 14 & 0 & CVA \\
13 & 14 & 32 & 0 & CVA \\
14 & 6 & 6 & $12 \cdot 0(14 \cdot 8)$ & \\
15 & 6 & 7 & & \\
Mean & $7 \cdot 1(3 \cdot 6)$ & $19 \cdot 2(14 \cdot 9)$ & & \\
(SD) & & & & \\
\hline
\end{tabular}

CVA, cerebral vascular accident; $L V T$, left ventricular thrombus.

who did not receive anticoagulants had a cerebrovascular accident, whereas 13 of the 40 patients with thrombus who received warfarin had peripheral emboli ( $p=N S)$. All but one of the patients on warfarin had a Thrombotest of $<10 \%$ at the time of embolisation. Table 4 lists the time from the onset of the acute infarction to the diagnosis of a thrombus and peripheral emboli, the location of peripheral emboli, and the time of anticoagulation treatment before the formation of peripheral emboli. No bleeding episodes were diagnosed.

None of the 15 patients with a left ventricular thrombus and peripheral embolisation had a previous history or clinical signs of peripheral arterial or carotid artery disease, cardiac valve disease, or other conditions predisposing to emboli. Among the patients who were under observation in the hospital at the time of the embolic event, none had hypotension or atrial fibrillation.

Computerised cerebral tomography was performed in 10 of the 14 patients with acute neurological deficits. All 10 had abnormal scans showing multiple infarctions in seven patients and a large single infarction in three patients.

\section{Discussion}

The current study defines several features that predict a high risk of peripheral embolisation in patients with an acute anterior infarction and $a$ left ventricular thrombus. Old age, a pendulous thrombus, and a mobile thrombus were associated with high embolic rates. The sensitivity and specificity of the mathematical logistic regression equation that combined echocardiographic measurements and patient age were sufficiently high to be clinically useful.

Single plane measurements of the thrombi and ventricles may not show the true volume of these: three dimensional structures. But biplane imaging is? often complicated by poor image quality in the apica? two chamber view. Use of volumes calculated from the area and long axis of the ventricle would only? introduce a derived variable that does not increase the amount of information collected from the primary data.

The equation indicates that for a given thrombus area the risk of embolisation increases with thew degree to which the thrombus projects into the ventricular lumen. The risk of embolisation is higher? with slender pendulous thrombi than with broad, mural thrombi. These variables were measured from ${ }^{\text {i }}$ the silhouette of the thrombi at the examination when $\vec{p}$ the thrombus was first definitely diagnosed. Later changes in thrombus features, such as the? develoment of central echolucency or independent thrombus motion, did not affect the embolic risk calculated from this equation. Therefore, the equa- $\frac{-5}{5}$ tion, based on the appearance of the thrombus at the time of diagnosis, may be a better predictor of risk $k_{\infty}^{\circ}$ than the visual variables, which depend upon time- $-\infty$ consuming serial observations of the thrombi and may show changes with time that may reduce theirs predictive value. ${ }^{12}$

An earlier retrospective study found that large thrombi increased the risk of peripheral emboli. ${ }^{100} \Omega$ However, in the present study, thrombus size, as estimated from thrombus area, was not significantly 3 larger in patients with emboli than in those without. In addition, only one of the 10 larger thrombi waș. associated with embolisation, suggesting that thrombus size alone does not predict the risk of periphera emboli.

The long axis of the ventricle in the patients with thrombi and emboli was slightly larger than that in patients with thrombi and no emboli. We do not know whether a longer axis affects the apica $\bar{b}$ haemodynamics in patients with an apical thrombus and thereby influences the embolic tendency.

Age $>68$ years, which did not correlate with the other variables in the equation, identified $80 \%$ of theo patients with peripheral emboli with a specificity of $85 \%$. Thus in patients aged $>68$, the mere presences of a thrombus seems to predict peripheral emboli as $\sigma$ accurately as detailed measurements. In those aged $<68$, embolisation was uncommon, but additiona: thrombus variables increased the accuracy of predic-s tion of peripheral emboli. The cause of the apparent increase in embolic risk with age is uncertain. Ano earlier study found no significant age differenced between patients with thrombi who had emboli and those who did not. ${ }^{13}$ 
It is difficult to diagnose a cerebral event as embolic on the basis of clinical symptoms alone. Some embolic events were not diagnosed, either because they were silent or because they caused mild transient symptoms. Many emboli to the abdominal circulation are not diagnosed during life because they do not cause symptoms. Thus we have probably underestimated the incidence of embolisation.

Most of the peripheral emboli $\left(80^{\circ}{ }_{0}\right)$ were strokes, and it is possible that some were caused by conditions other than embolisation, such as local thrombosis. In addition, elderly patients with coronary artery disease are at an increased risk of cerebrovascular atherosclerosis. None the less, none of the 15 patients with thrombus and embolisation had evidence of carotid artery disease. Moreover, seven of 10 patients who were examined by cerebral tomography had multiple cerebral infarctions, which indicates an increased likelihood of an embolic aetiology. The low frequency $\left(2^{\circ}{ }_{0}\right)$ of cerebrovascular accidents in the 95 patients without thrombi, who were otherwise clinically similar to the patients with thrombi, also underscores the high likelihood that most of the cerebrovascular events were embolic.

The inclusion of consecutive patients avoids selection bias. We included 11 with poor quality images, but none of them were classified as having thrombi and it is possible that thrombi were missed in some of these patients. However, no embolic events occurred in this group. Overall, only two of 95 patients in whom a thrombus was not detected had a cerebrovascular accident. Even if these events were caused by emboli from the left ventricle, underdiagnosis of thrombi by echo seems to be limited.

Overall, we saw a thirteen-fold higher embolic rate in the thrombus group than in the patients without a clot. The embolic rate of $27^{\circ}$ o in patients with left ventricular thrombi accords with earlier reports, although the range is wide, from $0-35^{\circ} o^{1-13}$ to $38-$ $85^{\circ}{ }_{0}$, in patients not receiving any anticoagulants. ${ }^{67}$ Use of anticoagulants varied considerably in the previous studies and several were retrospective.

Our study was not designed to compare the effect of anticoagulants with that of no treatment on the rate of peripheral embolisation; however, it showed that there were emboli in as many as $32 \%$ of the patients with thrombi when heparin and warfarin were started after a thrombus had developed. This may suggest that all patients with anterior myocardial infarction should have prophylactic anticoagulation. Other reports seem to support this conclusion. ${ }^{2621-24}$

In summary, a detailed study of the cross sectional echocardiographic appearance of left ventricular thrombi after acute anterior myocardial infarction can accurately predict the risk of embolisation. In addition to echocardiographic features, advanced age is an independent risk factor.

We thank Dr John $\mathbf{R}$ Stratton for his invaluable advice and throughful comments on the paper.

\section{References}

1 Asinger RW, Mikell FL, Elsperger J, Hodges M. Incidence of left ventricular thrombosis after acute transmural myocardial infarction. $N$ Engl J Med 1981;306:297-302.

2 Johannessen K-A, Nordrehaug JE, von der Lippe G. Left ventricular thrombosis and cerebrovascular accident in acute myocardial infarction. Br Heart $J$ 1984;51:553-6.

3 Visser CA, Kan G, Lie KI, Durrer D. Left ventricular thrombus following acute myocardial infarction: a prospective serial echocardiographic study of 96 patients. Eur Heart J 1983;4:333-7.

4 Foale R, Smith G, Nihoyannopoulos P, Maseri A. Left ventricular thrombus in acute myocardial infarction: best left alone? Circulation 1984;70(suppl IV):310.

5 Reeder GS, Abdul JT, Seward JB. Detection of left ventricular thrombus with two-dimensional echocardiography. Circulation 1981;II:19.

6 Weinreich DJ, Burke JF, Pauletto FJ. Left ventricular mural thrombi complicating acute myocardial infarction. Ann Intern Med 1984;100:789-94.

7 Keating EC, Gross SA, Schlamowitz RA, et al. Mural thrombi in myocardial infarctions. Am J Med 1983;74:989-95.

8 Benichou M, Aubry J, Larbi MB. Detection of left ventricular thrombi in the acute phase of myocardial infarction by two-dimensional echocardiography: a series of 103 cases. Arch Mal Coeur 1983; 76/9:1012-9.

9 Haugland JM, Asinger RW, Mikell FL, Elsperger KJ, Hodges $M$. Embolic potential of left ventricular thrombus detected by two-dimensional echocardiography. Circulation 1984;70:588-98.

10 Meltzer RS, Visser CA, Kan G, Roelandt J. Twodimensional echocardiographic appearance of left ventricular thrombi with systemic emboli after myocardial infarction. Am J Cardiol 1984;33:1511-3.

11 Visser CA, Kan G, Meltzer RS, et al. Embolic potential of left ventricular thrombus after myocardial infarction: a two-dimensional echocardiographic study of 119 patients. J Am Coll Cardiol 1985;5:1276-80.

12 Domenicucci S, Bellotti P, Chiarella F, Lupi G, Vecchi C. Spontaneous morphologic changes in left ventricular thrombi: a prospective two-dimensional echocardiographic study. Circulation 1987;75: 737-43.

13 Stratton JR, Resnick A. Increased embolic risk in patients with left ventricular thrombi. Circulation 1987;75:1004-11.

14 Johannessen K-A. Peripheral emboli from left ventricular thrombi of different echocardiographic appearance in acute anterior myocardial infarction. Arch Intern Med 1987;147:641-4. 
15 Arvan S, Plehn J. Embolization of a left ventricular mural thrombus: verification by two-dimensional echocardiography. Arch Intern Med 1982;142: 1952-3.

16 Arvan S. Persistent intracardiac thrombi and systemic embolism despite anticoagulant therapy. Am Heart $\mathrm{J}$ 1985;109:178-81.

17 Patterson BB, Puls JL. Standardization of prothrombin and activated partial thromboplastin time reagents and controls. Am J Clin Pathol 1976;65:213-9.

18 Owren PA. Control of anticoagulant therapy. The use of new tests. Arch Intern Med 1963;111:248-58.

19 Johannessen K-A, Nordrehaug JE, von der Lippe G. Increased occurrence of left ventricular thrombi during early treatment with timolol in patients with acute myocardial infarction. Circulation 1987;75: 151-5.

20 Engelman L. Stepwise logistic regression (SLR). In:
Johannessen, Nordrehaug, von der Lippe, Vollse

Dixon WJ, ed. BMDP statistical software. Berkley

University of California Press, 1983: 330-44.
21 Johannessen K-A, Nordrehaug JE, von der Lippe $G_{-}^{C}$ Prevention of left ventricular thrombi during acute myocardial infarction with inravenous heparin and oral warfarin. Circulation 1984;70(suppl IV):391 .

22 Nordrehaug JE, Johannessen $\mathrm{K}-\mathrm{A}$, von der Lippe $\mathrm{G}_{\overline{\mathrm{g}}}$. Usefulness of high-dose anticoagulants in preventing left ventricular thrombus in acute myocardial infarce tion. Am J Cardiol 1985;55:1491-3.

23 Report of the Working Party on Anticoagulation Therapy and Coronary Thrombosis to the Medica? Research Council. Assessment of short-term anticoagulant administration after cardiac infarctiono Br Med J 1969;i:335-42.

24 Veterans Administration Hospital Investigators Anticoagulants in acute myocardial infarction? JAMA 1973;225:724-9. 